\title{
Gas Sensing Properties of Powder Prepared from Waste Thermoelectric Devices by Wet Reduction Process
}

\author{
Hyeongsub So*, Dong-Ha Im**, Hyunsung Jung**;, and Kun-Jae Lee** \\ *Department of Energy Engineering, Dankook University, Cheonan 31116, Korea \\ **Nano Convergence Materials Center, Korea Institute of Ceramic Engineering and Technology, Jinju 52851, Korea
}

(Received November 23, 2017; Revised December 3, 2017; Accepted December 11, 2017)

\begin{abstract}
In this study, n-type $\mathrm{Bi}_{2} \mathrm{Te}_{3}$ in thermoelectric scrap is recovered through a wet reduction process. The recovered powder (tellurium) is grafted onto gas sensor in a new application that is not a thermoelectric device. Bismuth-rich powder is prepared by adding hydrazine when $\mathrm{pH}$ of the solution is brought to 13 using $\mathrm{NaOH}$. The $\mathrm{pH}$ of the filtered solution was reduced using $\mathrm{HNO}_{3}$, and then hydrazine was added to perform the re-reduction reaction. The tellurium-rich powder can be obtained through this reaction. The elemental analysis for these powders is confirmed by energy dispersive X-ray spectroscopy (EDS) analysis ; the successful separation of bismuth and tellurium is confirmed. Separated tellurium powder is mixed with DMF solvent and ethyl cellulose binder to confirm gas sensing properties. The tellurium paste was exposed in $\mathrm{NO}_{\mathrm{x}}$ atmosphere and exhibited a rapid reaction rate and recovery rate of less than 3 minutes for the gas.
\end{abstract}

Key words : Sensors, Powders, Recovering, Chemical reduction

\section{Introduction}

$\mathrm{T}$ he enforcement of regulations on environmental pollution caused by industrialization has highlighted the need for qualitative tools to detect the release of toxic gases and their concentrations. While gas chromatography is usually employed in odor and gas analysis, this method involves expensive equipment that is not easy to transport or operate. The development of low-cost and objective gas sensors as an effective method of detecting toxic or combustible gases and measuring their concentrations based on physical and chemical properties has been attracting interest.

Gas sensors can be largely categorized into semiconductor gas sensors, solid electrolyte gas sensors, and catalytic combustible gas sensors. ${ }^{1-3)}$ Semiconductor gas sensors are known for their outstanding sensitivity and response rate; they last longer than other types of gas sensors. These sensors make use of the change in electrical conductivity that occurs when a semiconductor surface comes into contact with gas. The change is electrical conductivity is induced by the varying of the width of the depletion layer due to the movement of electrons when a gas is adsorbed onto the semiconductor surface. ${ }^{4,5)}$ In 1962 , Seiyama et al. proposed a

\footnotetext{
${ }^{\dagger}$ Corresponding author: Hyunsung Jung

E-mail : hsjung@kicet.re.kr

Tel : +82-55-792-2711 Fax : +82-55-792-2704

"Corresponding author: Kun-Jae Lee

E-mail : kjlee@dankook.ac.kr

Tel : +82-41-550-3684 Fax : +82-41-559-7914
}

metal oxide $\left(\mathrm{MO}_{\mathrm{x}}\right)$ semiconductor gas sensor using $\mathrm{ZnO}_{2}$ films, and this has led to extensive research on semiconductor gas sensors to this day. ${ }^{6}$

Gas sensors are classified into n-type or p-type depending on the change in direction of conductivity when exposed to a reducing gas. $\mathrm{N}$-type gas sensors have electrons as their majority charge carriers, and show an increase in conductivity upon reacting with a reducing gas. On the other hand, ptype gas sensors have positive holes as their majority charge carriers, and exhibit an increase in conductivity upon reacting with an oxidizing gas. Tellurium (Te) shows p-type conduction because its lattice defects act as acceptors. ${ }^{7)}$ Te has a band gap of $0.34 \mathrm{eV}$, a carrier concentration of $(1-5) \times 10^{18} \mathrm{~cm}^{-3}$ at room temperature, and a Hall mobility of $20^{-5} \mathrm{~cm}^{2} / \mathrm{Vs}^{8}{ }^{8}$ According to some studies, Te-based gas sensors have fast response and satisfactory sensitivity in the range of ppm and sub-ppm concentrations. ${ }^{9,10)}$ Their flexible structure and high compatibility with alloys allow the material to assume different properties under various conditions, and sensors can be designed to suit a wide range of gases.

Te, which is a key element of thermoelectric materials, has seen an increase in demand with industrialization and is widely used in many fields (thermoelectric semiconductor, PV cell, catalyst etc.). ${ }^{11)}$ The rapid increase in demand since the 2000s has resulted in unstable prices of thermoelectric materials, and supply has grown limited due to restrictions imposed by resource-rich countries. ${ }^{12)}$ Because Te-based compounds are only available as imports in some countries and have an extremely low rate of reusability, it is necessary to cut down on costs from the material stage by devel- 
oping recycling technology and more economic processes. ${ }^{13)}$ In spite of this, few studies exist on the recovery of thermoelectric materials from thermoelectric scrap and on their integration in new applications. This study recovered thermoelectric scrap using a wet reduction process and, to analyze the gas sensing properties, created a Te paste from separated Te powder.

\section{Experimental Procedure}

\subsection{Recovery of Tellurium}

The particles to be used in examining gas sensing properties were prepared as follows. After heating the waste thermoelectric modules at $250^{\circ} \mathrm{C}$, soldered n-type $\left(\mathrm{Bi}_{2} \mathrm{Te}_{3}\right)$ and $\mathrm{p}$ type $\left(\mathrm{Bi}_{0.5} \mathrm{Te}_{1.5} \mathrm{Te}_{3}\right)$ chips were separated from the modules. To free the chip surface of residual solder, the separated chips were placed in $\mathrm{HCl}$ (37\%, Sigma-Aldrich Co., Ltd., USA) for six hours.

For classification of materials into n-type and p-type, 0.14 mmol of chips were each immersed in $30 \mathrm{~mL}$ of solution, comprised of $\mathrm{HNO}_{3}(70 \%$, Sigma-Aldrich Co., Ltd., USA) and $\mathrm{H}_{2} \mathrm{O}$ in the ratio of 2 to 1 , and dissolved for $24 \mathrm{~h}$. A syringe filter was used to extract solid p-type chips and to remove impurities existing in the recovered solution.

$\mathrm{NaOH}$ (98\%, DAEJUNG) was added to the filtered solution to adjust the $\mathrm{pH}$ to 13 . At $\mathrm{pH} 13,3 \mathrm{ml}$ of $\mathrm{N}_{2} \mathrm{H}_{4} \cdot \mathrm{H}_{2} \mathrm{O}$ (100\%, ACROS ORGANICS) was added, and reduction reactions were allowed to occur for $12 \mathrm{~h}$ at $70^{\circ} \mathrm{C}$. Once reactions were complete, a centrifuge and syringe filter were used to obtain an aqueous solution containing Te ions, and particles were retrieved in the form of dried powder. $\mathrm{HNO}_{3}$ was again used to adjust the $\mathrm{pH}$ of the Te-containing solution to 7 , and $2.184 \mathrm{~g}$ of cetyltrimethylammonium bromide (CTAB) was added. Next, $\mathrm{N}_{2} \mathrm{H}_{4} \cdot \mathrm{H}_{2} \mathrm{O}$ was added for re-reduction at $70^{\circ} \mathrm{C}$. The resulting powder was dried after washing with ethanol and DI water, and analyzed using X-ray diffraction (XRD), field emission scanning electron microscopy (FE-SEM) and energy dispersive X-ray spectroscopy (EDS). Te powder was used to examine the gas sensing properties.

\subsection{Sample Analysis}

The crystal structure of the resulting powder was subject to XRD (ULTIMA IV, Rigaku) analysis, with $\mathrm{Cu} \mathrm{K \alpha}(\lambda=$ $0.154 \mathrm{~nm}$ ) radiation at $40 \mathrm{kV}, 40 \mathrm{~mA}$. The particle shapes were analyzed using FE-SEM (S-4300, Hitachi) and, at the same time, elemental analysis was performed through EDS (EDAX Pegasus 4040, EDAX). Concentrations were varied by controlling the flow of the target gas and air with a mass flow controller (Alicat, MC-500SCCM-D); sample resistance under varying concentrations was measured in real-time with a multimeter (Keithley-2000).

\subsection{Preparation and Measurement of Gas Sensor Properties}

To assess the gas sensing properties of Te powder obtained through re-reduction, Te paste was prepared by mixing the
Te powder with DMF solvent and ethyl cellulose binder. Te paste was handprinted on $\mathrm{Si}$ wafers containing $\mathrm{SiO}_{2}$ layers with interdigitated $\mathrm{Au}$ electrodes deposited at an interval of $200 \mu \mathrm{m}$; samples were then dried for $24 \mathrm{~h}$ at $80^{\circ} \mathrm{C}$. Measurements were taken after stabilizing the resistance of samples at room temperature. The total flow of $\mathrm{NO}_{\mathrm{x}}$ gas and air was fixed at $500 \mathrm{sccm}$, and measurements were obtained using a mass flow controller to vary the concentration of $\mathrm{NO}_{\mathrm{x}}$ gas from $10 \mathrm{ppm}$ to $50 \mathrm{ppm}$.

\section{Results and Discussion}

Figure 1 shows the results of XRD analysis for the powder prepared with a precursor solution in which n-type chips were dissolved. Fig. 1(a) shows the XRD patterns of samples prepared by adding hydrazine in the absence of $\mathrm{NaOH}$. Diffractions of (015), (1010), and (110) were observed at $27.6^{\circ}$, $37.8^{\circ}$, and $41.1^{\circ}$ respectively. Both $\mathrm{Bi}$ and Te ions reacted with samples not containing $\mathrm{NaOH}$, and formed a $\mathrm{Bi}_{2} \mathrm{Te}_{3}$ hexagonal crystal structure (JCPDS \#15-0863) having an R $\overline{3} \mathrm{~m}$ (166) space group. Fig. 1(b) shows the results for samples reduced after adding $\mathrm{NaOH}$ and adjusting the $\mathrm{pH}$ to 13 . Diffractions of (100), (101), (102), and (110) were observed at $23.0^{\circ}, 27.5^{\circ}, 38.2$, and $40.4^{\circ}$, respectively. When hydrazine is added at $\mathrm{pH} 13$, the reduction process is centered around $\mathrm{Bi}$ because, at this $\mathrm{pH}$, Te exists as $\mathrm{TeO}_{3}{ }^{2-}$ and $\mathrm{Bi}$ as $\mathrm{Bi}_{2} \mathrm{O}_{3}$. The reduction of $\mathrm{Bi}_{2} \mathrm{O}_{3}$ takes place with hydrazine acting as a strong reducing agent. The $\mathrm{Bi}$ hexagonal crystal structure (JCPDS \#44-1246) was found to contain the $\mathrm{R} \overline{3} \mathrm{~m}$ (166)

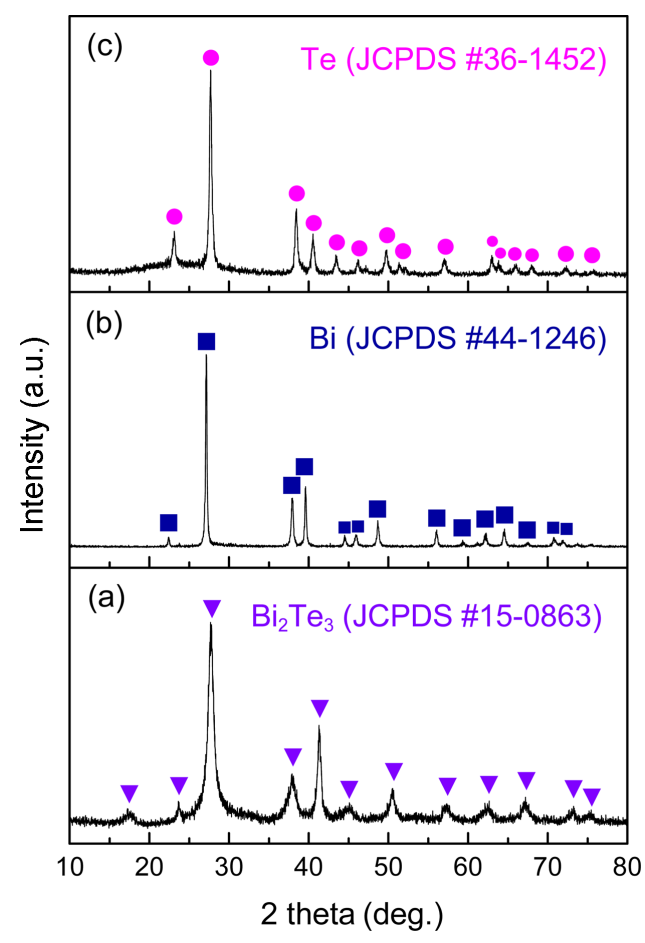

Fig. 1. XRD patterns of powders prepared by wet reduction reaction using waste thermoelectric module with respect to conditions: (a) raw $\mathrm{pH}$; (b) $\mathrm{pH} 13$; (c) $\mathrm{pH} 7$. 

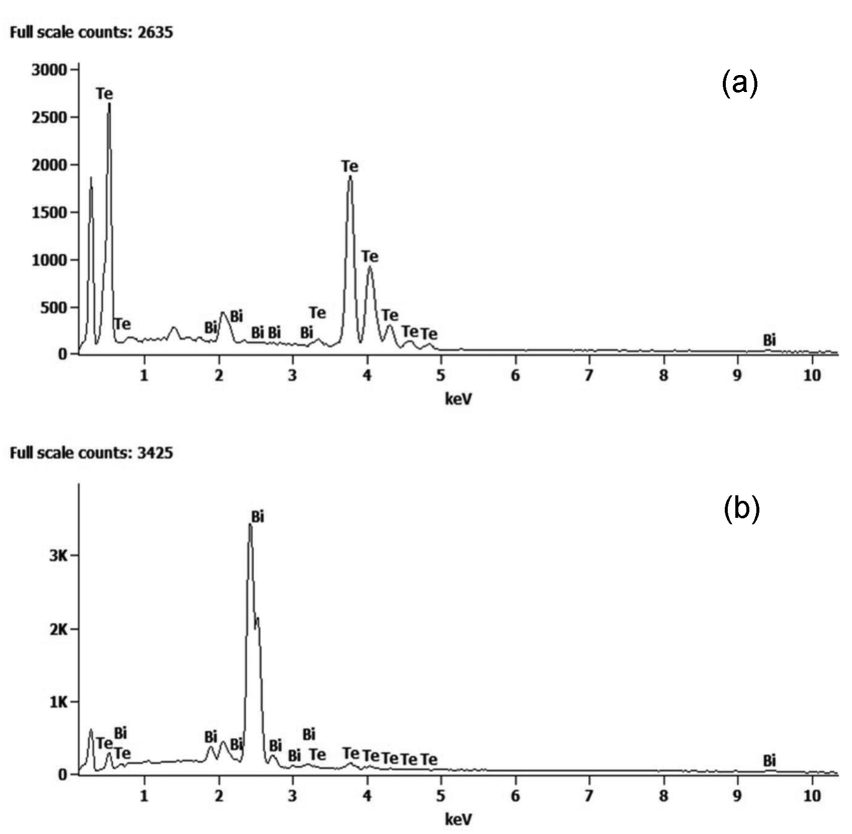

Fig. 2. EDS peaks of powders prepared with respect to conditions: (a) tellurium; (b) bismuth.

space group. Fig. 1(c) shows the results for samples that have undergone re-reduction after adding $\mathrm{NaOH}$ to obtain a $\mathrm{pH}$ of 7. Diffractions of (100), (101), (102), and (110) were observed at $23.0^{\circ}, 27.6^{\circ}, 38.3^{\circ}$, and $40.4^{\circ}$, and the Te hexagonal crystal structure (JCPDS \#36-1452) was found to contain the $\mathrm{P} 3_{1} 21$ (152) space group. The equations below express the behavior and reduction reaction of $\mathrm{Bi}$ at $\mathrm{pH} 13$.

$$
\begin{aligned}
& 6 \mathrm{Bi}+6 \mathrm{HNO}_{3} \rightarrow \mathrm{Bi}_{2} \mathrm{O}_{3}+6 \mathrm{NO}_{2}+3 \mathrm{H}_{2} \mathrm{O} \\
& \mathrm{Bi}_{2} \mathrm{O}_{3}+\mathrm{N}_{2} \mathrm{H}_{4} \rightarrow 2 \mathrm{Bi}+2 \mathrm{NO}+\mathrm{H}_{2} \mathrm{O}+\mathrm{H}_{2} \uparrow
\end{aligned}
$$

The powders prepared at different levels $\mathrm{pH}$ were analyzed, as shown in Fig. 2, using EDS. Both Te and Bi were detected. To check for the separation of Te from $\mathrm{Bi}$, the analysis excluded carbon and oxide, focusing only on $\mathrm{Bi}$ and $\mathrm{Te}$. The peak exhibited at $0.175 \mathrm{keV}$ is the $\mathrm{C}$ peak. In Fig. 2(a), Te peaks can be clearly seen at $0.46 \mathrm{keV}, 3.75 \mathrm{keV}, 4.03$ $\mathrm{keV}$, and $4.31 \mathrm{keV}$, and these results are consistent with the Te EDX results. Some Bi peaks were also analyzed. Most peaks in Fig. 2(b) are peaks of $\mathrm{Bi}$; peaks matching Bi were observed at $2.04 \mathrm{keV}, 2.43 \mathrm{keV}$, and $2.71 \mathrm{keV}$. Similar to the previous samples, some Te peaks were included in the analysis. Table 1 presents the results of quantitative analysis in wt.\% and at.\% for Te and Bi.

Figure 3 gives the FE-SEM results for particles prepared under varying $\mathrm{pH}$ conditions. The samples in Fig. 3(a), which have been reduced after adding $\mathrm{NaOH}$ but without changing $\mathrm{pH}$, have spherical particles. As shown in Fig. 3(b), the samples reduced at $\mathrm{pH} 13$ have irregular particles. The particles in Fig. 3(c) were obtained after adding CTAB and performing reduction at $\mathrm{pH}$ 7. These samples have distinct shapes and are more coarsely coagulated compared to
Table 1. The EDS Element Analysis of the Reduced Sample at $\mathrm{pH} 13$ and $\mathrm{pH} 7$

\begin{tabular}{cccc}
\hline & \multirow{2}{*}{ Components } & \multicolumn{2}{c}{ Amount } \\
\cline { 3 - 4 } & & wt.\% & at.\% \\
\hline \multirow{2}{*}{$\mathrm{pH} 13$} & $\mathrm{Te}$ & 2.92 & 4.69 \\
& $\mathrm{Bi}$ & 97.08 & 95.31 \\
\hline \multirow{2}{*}{$\mathrm{pH} 7$} & $\mathrm{Te}$ & 99.50 & 99.69 \\
& $\mathrm{Bi}$ & 0.50 & 0.31 \\
\hline
\end{tabular}

(a)
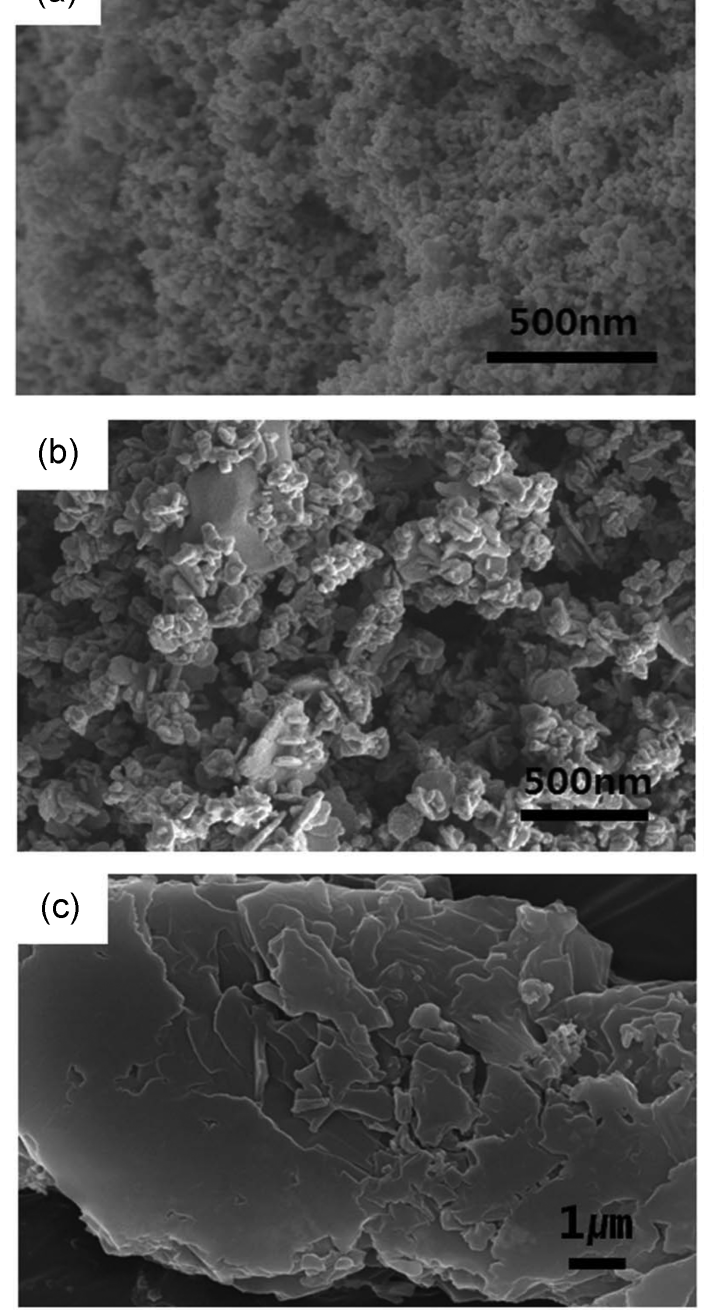

Fig. 3. FE-SEM images of prepared powders with respect to conditions: (a) $\mathrm{Bi}_{2} \mathrm{Te}_{3}$; (b) bismuth; (c) tellurium.

the other samples.

Figure 4 shows the $\mathrm{NO}_{\mathrm{x}}$ gas sensing properties of Te paste recovered from printing $\mathrm{CTAB}$ on interdigitated $\mathrm{Au}$ electrodes. The concentrations of $\mathrm{NO}_{\mathrm{x}}$ in the gas chamber were set at $10 \mathrm{ppm}, 25 \mathrm{ppm}$, and $50 \mathrm{ppm}$. Table 2 presents the response rate $\left(\mathrm{T}_{90}\right.$ : time needed to reach $90 \%$ of resistance after gas exposure), recovery rate $\left(\mathrm{D}_{10}\right.$ : time needed to recover $10 \%$ of current signal value after removing gas), and sensitivity $\left(\mathrm{R}_{\mathrm{a}} / \mathrm{R}_{\mathrm{g}}, \mathrm{R}_{\mathrm{a}}\right.$ : resistance of sample in atmosphere, $\mathrm{R}_{\mathrm{g}}$ : 


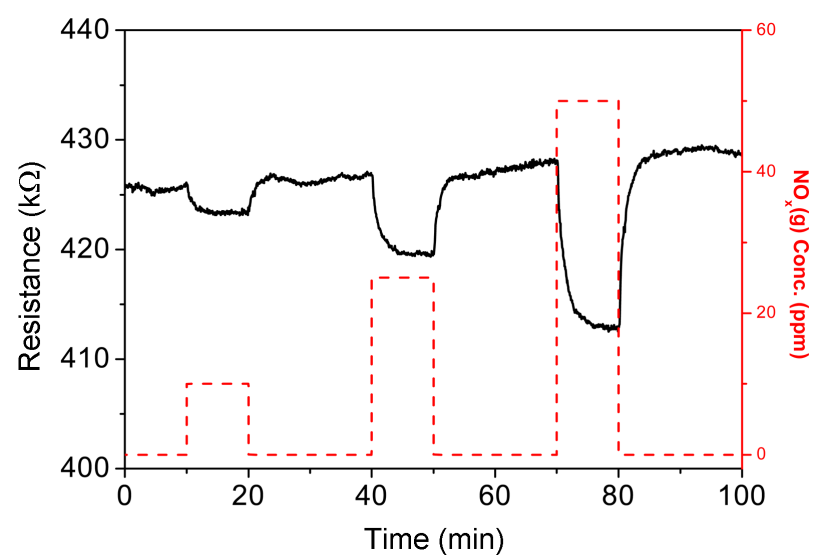

Fig. 4. Gas sensing characterization for $\mathrm{NO}_{\mathrm{x}}$ in $\mathrm{CTAB}$-added Te paste.

Table 2. Sensitivity, Reaction Rate and Recovery Rate for $\mathrm{NO}_{\mathrm{x}}$ Gas Sensing at Different Concentration of CTAB-added Te Paste

\begin{tabular}{cccc}
\hline $\begin{array}{c}\mathrm{NO}_{\mathrm{x}}(\mathrm{g}) \\
\text { concentration }\end{array}$ & $\begin{array}{c}\text { Sensitivity } \\
\left(\mathrm{R}_{\mathrm{a}} / \mathrm{R}_{\mathrm{g}}\right)\end{array}$ & $\begin{array}{c}\text { Response } \\
\text { time } \\
\left(\mathrm{T}_{90}\right)\end{array}$ & $\begin{array}{c}\text { Recovery } \\
\text { time } \\
\left(\mathrm{D}_{10}\right)\end{array}$ \\
\hline $50 \mathrm{ppm}$ & 1.035 & $191 \mathrm{sec}$ & $186 \mathrm{sec}$ \\
$25 \mathrm{ppm}$ & 1.017 & $179 \mathrm{sec}$ & $108 \mathrm{sec}$ \\
$10 \mathrm{ppm}$ & 1.006 & $107 \mathrm{sec}$ & $80 \mathrm{sec}$ \\
\hline
\end{tabular}

resistance upon exposure to target gas) at different concentrations. Sensitivity increased linearly as $\mathrm{NO}_{\mathrm{x}}(\mathrm{g})$ concentration rose from $10 \mathrm{ppm}$ to $50 \mathrm{ppm}$, and reaction and recovery rates fell below three minutes. The decreasing resistance of the Te paste upon interaction with the oxidizing gas $\mathrm{NO}_{\mathrm{x}}(\mathrm{g})$ indicates an increase in the number of positive holes as charge carriers in Te; this material exhibits the properties of p-type semiconductors.

\section{Conclusions}

This study dissolved waste thermoelectric modules in an $\mathrm{HNO}_{3}$ aqueous solution and adjusted the $\mathrm{pH}$ to separate $\mathrm{Bi}$ and Te particles using a wet reduction process. The powders were prepared under different conditions, and XRD analysis revealed a single spectrum of $\mathrm{Bi}$ at $\mathrm{pH} 13$ and of Te at $\mathrm{pH} 7$. Under EDS analysis, Bi was found to constitute most of the reduced particles at $\mathrm{pH} 13$, while Te with $99 \%$ purity was observed in the reduced particles at $\mathrm{pH}$ 7. These results confirm that elements can be easily separated for n-type $\left(\mathrm{Bi}_{2} \mathrm{Te}_{3}\right)$ conductors through $\mathrm{pH}$ adjustments. The Te particles, after separation from $\mathrm{Bi}$, were integrated into a new application. Gas sensing properties were determined under $\mathrm{NO}_{\mathrm{x}}$ gaseous atmosphere with the Te paste, which was pre- pared by mixing Te powder with DMF solvent and ethyl cellulose binder. The sensitivity, reaction rate, and recovery rate increased in proportion with the gas concentration. The paste exhibited a fast reaction rate and a recovery rate of less than three minutes at various concentrations.

\section{REFERENCES}

1. S. R. Morrison, "Mechanism of Semiconductor Gas Sensor Operation," Sens. Actuators, 11 [3] 283-87 (1987).

2. G. Korotcenkov, "Metal Oxides for Solid-State Gas Sensors: What Determines Our Choice?," Mater. Sci. Eng. B, 139 [1] 1-23 (2007).

3. C.-H. Han, D.-W. Hong, S.-D. Han, J. Gwak, and K. C. Singh, "Catalytic Combustion Type Hydrogen Gas Sensor Using $\mathrm{TiO}_{2}$ and UV-LED," Sens. Actuators, B, 125 [1] 22428 (2007).

4. N. Yamazoe, G. Sakai, and K. Shimanoe, "Oxide Semiconductor Gas Sensors," Catal. Surv. Asia, 7 [1] 63-75 (2003).

5. A. Rothschild and Y. Komem, "The Effect of Grain Size on the Sensitivity of Nanocrystalline Metal-Oxide Gas Sensors," J. Appl. Phys., 956374 (2004).

6. T. Seiyama, A. Kato, K. Fujiishi, and M. Nagatani, "A New Detector for Gaseous Components Using Semiconductive Thin Film," Anal. Chem., 34 [11] 1052-53 (1962).

7. N. Bârsan, M. Huebner and U. Weimar, "Conduction Mechanism in Semiconducting Metal Oxide Sensing Films: Impact on Transduction," pp. 35-63 in Semiconductor Gas Sensors. Ed. by R. Jaaniso and O. K. Tan, Woodhead Publishing Series, Sawston Cambridge, 2013.

8. D. Tsiulyanu, "Tellurium Thin Films in Sensor Technology," pp. 363-80 in Proceedings of the NATO Advanced Study Institute on Nanotechnological Basis for Advanced Sensors, Sozopol, Bulgaria, 2010.

9. D. Tsiulyanu, A. Tsiulyanu, H.-D. Liess, and I. Eisele, "Characterization of Tellurium-based Films for $\mathrm{NO}_{2}$ detection," Thin Solid Films, 485 [1-2] 252-56 (2005).

10. T. Siciliano, E. Filippo, A. Genga, G. Micocci, M. Siciliano, and A. Tepore, "Single-Crystalline Te Microtubes: Synthesis and $\mathrm{NO}_{2}$ Gas Sensor Application," Sens. Actuators, B, 142 [1] 185-90 (2009).

11. K. J. Lee, Y. H. Jin, and M. S. Kong, "Synthesis of the Thermoelectric Nanopowder Recovered from the Used Thermoelectric Modules," J. Nanosci. Nanotechnol., 14 [10] 7919-22 (2014).

12. C. Candelise, M. Winskel, and R. Gross, "Implications for CdTe and CIGS Technologies Production Costs of Indium and Tellurium Scarcity," Prog. Photovolt: Res. Appl., 20 [6] 816-31 (2012).

13. H. U. Sverdrup, K. V. Ragnarsdottir, and D. Koca, "An Assessment of Metal Supply Sustainability as an Input to Policy: Security of Supply Extraction Rates, Stocks-in-Use, Recycling, and Risk of Scarcity," J. Clean. Prod., 140 [1] 359-72 (2017). 